\title{
Calidad de vida percibida en inmigrantes sudamericanos en el norte de Chile
}

\author{
Quality of life in south american immigrants in north Chile
}

\author{
Alfonso Urzúa* \\ María Vega \\ Alexandra Jara \\ Susana Trujillo \\ Roxana Muñoz \\ Escuela de Psicología, Universidad Católica del Norte, Chile \\ Alejandra Caqueo-Urízar. \\ Departamento de Psicología, Universidad de Tarapacá, Chile
}

(Rec: 15 abril 2015 / Acept: 15 junio 2015)

\begin{abstract}
Resumen
Bajo un diseño transversal se analiza el efecto de variables socio-demográficas, económicas y relacionales sobre la calidad de vida (CV) en 421 inmigrantes peruanos y colombianos en el norte de Chile. Para evaluar la CV se utilizó el cuestionario WHOQoL-Bref y un cuestionario sociodemográfico. Los resultados muestran que el dominio mejor evaluado en ambas poblaciones fue el físico, en tanto el peor evaluado fue el ambiental. Las variables sociodemográficas que resultaron con mayor predicción en los dominios fueron la edad, nivel de ingresos mensuales, con quien vive y si se encuentra en pareja. Este estudio espera contribuir al desarrollo de políticas migratorias integrales, sobre todo en torno a la $\mathrm{CV}$ de las personas que viven el proceso migratorio día a día, a fin de fomentar su bienestar, prevenir problemas de salud, así como fomentar la integración y la adaptación a la nueva cultura.

Palabras clave: inmigración, calidad de vida y bienestar.
\end{abstract}

\begin{abstract}
Under a cross-sectional design, we analyzed the effect of socio-demographic-economic-relational variables on quality of life (QoL) in a sample of 421 Peruvian and Colombian immigrants in northern Chile. To assess the QoL was used the WHOQOL-Bref and a sociodemographic questionnaire. The results show that the best domain assessed in both populations was the physical, while the worst was the environmental domain. Sociodemographic variables that were most predictive in the domains were age, level of monthly income, with whom you live and whether you are a couple. This study hopes to contribute to the development of comprehensive migration policies, especially regarding the QoL of people living daily migration process, to promote their well-being, prevent health problems and to promote the integration and adaptation to the new culture.

Keywords: immigration, quality of life, well being.
\end{abstract}

Correspondencia: Dr. Alfonso Urzúa, Escuela de Psicología, Universidad Católica del Norte, Avda. Angamos 0610, Antofagasta, Chile. Email: alurzua@ ucn.cl

Nota: Estos resultados son parte de la investigación derivada del Proyecto FONDECYT 1140843, financiada por la Comisión Nacional de Ciencia y Tecnología CONICYT 


\section{Introducción}

La migración puede ser entendida como todo movimiento de personas, sea cual fuere su tamaño, composición o causas, hacia el territorio de otro Estado o dentro del mismo (OMS, 2006), implicando un conjunto de factores causales, de desarrollo y consecuencias, tanto para la sociedad de origen como para la de destino (Cano y Soffia, 2009).

Las consecuencias del proceso migratorio pueden ser descritas desde una perspectiva macro-social, la que analiza los efectos de la migración a nivel económico, social, político y cultural; y una micro-social, donde cobran relevancia las consecuencias en el plano íntimo, afectivo, emocional y entre otros (Vilar y Eibenschutz, 2007). Bajo este último enfoque, interesan las consecuencias a nivel de salud, bienestar o calidad de vida en cada persona, las cuales estarán mediadas, entre otras, por variables como si ha sido un viaje planificado o forzado, bajo qué condiciones se produce el proceso migratorio, forma de ingreso al país receptor, es decir, si éste se realiza en vía regular o irregular, los peligros al cruzar la frontera, el tiempo de estadía en el país (Vilar y Eibenschutz, 2007), el apoyo social percibido en el país de origen y en el receptor, si quien migra deja a su familia en su país de origen o si en el país receptor tiene un sitio de acogida con personas pertenecientes a su mismo país, condiciones de vida (Yáñez y Cárdenas, 2010), el nivel socioeconómico, nivel cultural, expectativas en el país de llegada, idioma y grado de similitud entre la cultura de acogida y la de origen que son variables que si bien pertenecen más a un enfoque macro social, tienen directa repercusión a nivel personal, ya que la persona va modulando estos nuevos cambios (Valiente, Sandín, Chorot, Santed y González de Rivera, 1996).

Las consecuencias más comunes del proceso migratorio se relacionan con problemas de salud física y mental, en el sentido económico con la escasez de recursos para satisfacer sus necesidades básicas, pobreza y condiciones de vida inhumanas, desempleo, marginación, invisibilización, discriminación y explotación (Valiente et al.,1996, Zarza y Sobrino, 2007), variables que influyen directamente en su calidad de vida y bienestar.

La calidad de vida es definida como la percepción que un individuo tiene de su lugar en la existencia, en el contexto de la cultura y en el sistema de valores en los que vive y en relación con sus objetivos, expectativas, normas e inquietudes (The WHOQoL Group, 1995). Operacionalmente puede describirse como el estado o sentimiento de bienestar derivado de la evaluación tanto objetiva como subjetiva del grado de satisfacción de la persona en distintas dimensiones de su vida (Urzúa y Caqueo-Urízar, 2012). Aún cuando no se ha podido encontrar literatura que describa cuáles son los efectos de la migración en la calidad de vida de quienes viven esta experiencia, se han encontrado reportes que describen cómo se comportan en población migrante variables altamente relacionadas con la $\mathrm{CV}$ como lo son el bienestar y la satisfacción con la vida.

Acerca de a la satisfacción con la vida, la evidencia indica que existiría una relación negativa entre la discriminación percibida y la satisfacción con la vida, incidiendo en los niveles de bienestar, no obstante, la autoestima presentaría una relación positiva con el sentido de identidad, ayudando a disminuir los efectos de la discriminación (Murillo y Molero, 2012).

Estudios han descrito que el bienestar subjetivo estaría asociado a un mayor tiempo de permanencia, al estatus legal, a una mayor afiliación, al apoyo de autóctonos, a una menor distancia cultural percibida entre los lugares de origen y acogida, a una menor discriminación social percibida, a acceso a vivienda y servicios básicos, al apoyo y percepción de apoyo de una red social, proporcionando en esta última una variable estructural (tamaño de la red social) y una variable funcional (nivel de satisfacción del apoyo social) (Basabe, Páez, Aierdi, Jiménez-Aristizábal, 2009; Basabe, Zlobina y Páez, 2004; Hernández, Pozo y Alonso, 2004; Sánchez y López, 2008). En Chile, estudios reportan que la integración a la nueva sociedad se traduce en mejores indicadores en las distintas dimensiones de bienestar psicológico (Yáñez y Cárdenas, 2010).

Chile no es reconocido mundialmente como país receptor de inmigrantes, pero sí se ha vuelto destino atractivo para personas y familias que buscan oportunidades y condiciones que no han encontrado en su país de origen, dados los buenos resultados económicos y las condiciones de seguridad del país. Esto ha producido un incremento migratorio destacable, siendo las migraciones provenientes de Perú, Ecuador y Colombia quienes están dentro de los nuevos grupos de llegada (CEPAL, 2006; Stefoni, 2011). La zona del Norte Grande de Chile ha recibido en los últimos años una numerosa cantidad de inmigrantes de origen latinoamericano, principalmente colombianos y peruanos, atraídos principalmente por la minería y los servicios derivados. El Censo 2012 reveló que el $70.5 \%$ de los extranjeros en Chile provenían de Sudamérica, principalmente peruanos $(30.5 \%)$, argentinos $(16.8 \%)$ y colombianos $(8.1 \%)$. Pese a este notable incremento, no existen estudios que caractericen los niveles de bienestar y calidad de vida de los inmigrantes, 
así como las variables vinculadas a ellos, surgiendo nuestras preguntas de investigación ¿Cómo es y cuáles son los factores que afectan la calidad de vida de los inmigrantes peruanos y colombianos en el norte de Chile?

En este marco, el objetivo de la investigación fue describir y analizar los factores que afectan la CV y sus dominios específicos (físico, psicológico, social y ambiental) en inmigrantes sudamericanos en el norte de Chile.

Dada la alta correlación entre la CV y el bienestar, es posible esperar que factores socio-demográficos, económicos y relacionales, tales como tiempo de permanencia en la ciudad, nivel de ingresos, nivel de estudios, autopercepción de fenotipo, situación administrativa, nivel de contacto con autóctonos, entre otras, puedan afectar la CV percibida de los encuestados. Con respecto a esto, se espera una mejor $\mathrm{CV}$ a un mayor tiempo de permanencia, mayor nivel de ingresos, fenotipo más caucásico, residencia legal y mayor contacto con autóctonos.

\section{Método}

\section{Participantes}

Se consideró como criterio de inclusión el ser ciudadano nacido en Colombia o Perú, hombre o mujer, mayor de edad, con una permanencia mínima de seis meses en la ciudad de Antofagasta. Todos los participantes accedieron de forma voluntaria a participar en la encuesta mediante la firma de un consentimiento informado. Los participantes semilla fueron encuestados principalmente en instituciones públicas tales como el Instituto Católico Chileno de Migración (INCAMI), Ciudadano Global-Servicio Jesuitas a Migrantes, Departamento de Extranjería y Migración, Consulado de Colombia y Perú, centros de salud, entre otros.

\section{Instrumento}

La CV fue evaluada a través del cuestionario WHOQolBREF (The WHOQOL Group, 1998). El cuestionario consta de 26 preguntas, de las cuales una inquiere sobre la CV general, otra sobre la satisfacción con su salud y las 24 restantes se agrupan en cuatro dominios: físico ( 7 preguntas), psicológico (6 preguntas), social (3 preguntas) y ambiental (8 preguntas), con opciones de respuesta entre 1 y 5 puntos. Se utilizó la versión en español (Lucas-Carrasco, 2012), para la cual se han reportado buenas propiedades psicométricas en su utilización en población chilena y sudamericana (Benítez, Guardia y Urzúa, 2014; Espinoza, Osorio, Torrejón, Lucas-Carrasco y Bonout, 2011; Urzúa y Caqueo-Urízar, 2013).

\section{Procedimiento}

El proyecto fue aprobado por los comités de ética de la Universidad Católica del Norte y de la Comisión Nacional de Ciencia y Tecnología - CONICYT. Los participantes fueron enrolados en un método mixto combinando el método de "bola de nieve", el cual consiste en seleccionar nuevas personas entre las redes sociales de los encuestados (Bernacki y Waldorf, 1981), y un muestreo intencionado, con el fin de completar las cuotas por nacionalidad, sexo y situación legal. La aplicación del instrumento duró 2 horas aproximadamente. La tasa de participación en el estudio fue de un $80 \%$. Los datos fueron ingresados en una base construida en el SPSS 17.0. Se calcularon estadísticos descriptivos para las variables CV y sus cuatro dominios, así como para cada una de las variables independientes evaluadas. Se realizan pruebas de diferencias de medias, ya sean t o ANOVA, para evaluar si existían diferencias entre los sexos, nacionalidad, o categorías de las variables evaluadas. Finalmente se efectúan regresiones por país considerando la CV y cada uno de los dominios evaluados como variables a predecir y las variables socio-demográficas, económicas $\mathrm{y}$ relacionales vinculadas como predictoras.

\section{Resultados}

\section{Participantes}

Fueron encuestadas 431 personas, de las cuales el $53.8 \%$ fueron de nacionalidad colombiana y el $46.2 \%$ de nacionalidad peruana, con edades entre 18 a 65 años. La caracterización de los participantes puede ser observada en la tabla 1.

La distribución de los participantes, según el máximo nivel de estudios alcanzado por nacionalidad, puede ser observada en la tabla 2

Más del 75\% de encuestados se encontraba activo laboralmente, con un ingreso mensual promedio en ambas nacionalidades entre los 100 y 300 mil pesos. La mayoría de los participantes indican encontrarse con permiso de residencia, con un tiempo de permanencia promedio para ambas nacionalidades entre uno y tres años. El detalle de esta caracterización socio-económica se encuentra en la tabla 3. 
Tabla 1. Distribución de resultados por sexo y edad, en población peruana y colombiana.

\begin{tabular}{|c|c|c|c|c|c|c|c|c|c|c|c|c|}
\hline & \multicolumn{6}{|c|}{ Sexo } & \multicolumn{6}{|c|}{ Edad } \\
\hline & \multicolumn{2}{|c|}{ hombre } & \multicolumn{2}{|c|}{ mujer } & \multicolumn{2}{|c|}{ Total } & \multicolumn{2}{|c|}{ hombre } & \multicolumn{2}{|c|}{ mujer } & \multicolumn{2}{|c|}{ Total } \\
\hline & $\mathrm{n}$ & $\%$ & $\mathrm{n}$ & $\%$ & $\mathrm{~N}$ & $\%$ & M & $\mathrm{DE}$ & M & $\mathrm{DE}$ & M & $\mathrm{DE}$ \\
\hline Colombianos & 111 & 47.80 & 121 & 52.20 & 232 & 53.80 & 32.59 & 8.67 & 32.40 & 9.65 & 32.49 & 9.17 \\
\hline Peruanos & 96 & 48.20 & 103 & 51.80 & 199 & 46.20 & 33.40 & 9.77 & 34.88 & 9.83 & 34.16 & 9.80 \\
\hline Total & 207 & 48.00 & 224 & 52.00 & 431 & 100 & 32.97 & 9.18 & 33.53 & 9.79 & 33.26 & 9.49 \\
\hline
\end{tabular}

Tabla 2. Nivel educacional declarado de población peruana y colombiana.

\begin{tabular}{lrrrr}
\hline & \multicolumn{3}{c}{ PE } & \multicolumn{3}{c}{ COL } \\
\hline Sin estudios primarios o enseñanza básica incompleta & $\mathrm{n}$ & \multicolumn{1}{c}{$\%$} & $\mathrm{~N}$ & $\%$ \\
Estudios primarios: estudios de enseñanza media básica, bachiller elemental & 29 & 10.10 & 21 & 9.10 \\
Estudios secundarios: enseñanza media, bachiller superior & 64 & 32.30 & 70 & 18.60 \\
Estudios técnicos incompletos & 31 & 15.70 & 27 & 11.70 \\
Estudios técnicos completos & 27 & 13.60 & 43 & 18.60 \\
Estudios universitarios medios: diplomaturas, estudios incompletos & 17 & 8.60 & 17 & 7.40 \\
Estudios universitarios superiores completos & 20 & 10.10 & 10 & 4.30 \\
\hline
\end{tabular}

Nota: PE: población peruana; COL: población colombiana.

Más del $60 \%$ de los participantes declara tener pareja, reportando cerca de dos tercios de la muestra estar viviendo con ella o con familiares. El detalle por país, así como el grado de contacto que tienen con chilenos y gente de la misma nacionalidad se encuentran en la tabla 4 .

Sobre la autopercepción de fenotipo, la mayoría de la población peruana se autodefinió como mestizo, mientras que la población colombiana como blanco/caucásico (tabla 5).

\section{Calidad de vida y variables sociodemográficas}

Al considerar la totalidad de los participantes, así como estratificando el análisis por sexo (tabla 6), podemos observar que el dominio mejor evaluado fue el físico, mientras que el dominio peor evaluado fue el ambiental. Al analizar las diferencias entre medias dadas por el sexo, se hallaron diferencias estadísticamente significativas en el dominio físico $\left(t=2.973_{(426) ;} p=.003\right)$, psicológico $\left(t=2.329_{(424,376)} p=.020\right)$ $\mathrm{y}$ en la satisfacción con la salud $\left(t=2.837_{(422,792) ;} p=0.005\right)$, donde la media de los hombres evaluados es mayor a la media de las mujeres en las dimensiones anteriores.

Al estratificar el análisis por país, se observa que el dominio físico fue el mejor evaluado por la población colombiana y peruana en ambos sexos, mientras el peor evaluado por los mismos grupos fue la dimensión ambiental.

$\mathrm{Al}$ analizar si existían diferencias de medias en los dominios de CV dado el país de origen (tabla 7), se encuentra que existen diferencias estadísticamente significativas en el dominio físico $\left(t=3.281_{(425,645)} p=.001\right)$, en el psicológico $\left(t=3.751_{(423,780) ;} p=.000\right)$ y en el social $\left(t=4.556_{(423,701) ;}\right.$ $p=.000$ ), donde la media de los colombianos evaluados es mayor que la media de los peruanos evaluados en todos los dominios anteriores.

Al evaluar diferencias de medias entre sexos por país, en la población colombiana se encontraron diferencias estadísticamente significativas sólo en la dimensión física, donde la media de los hombres es mayor a la de las mujeres $\left(f=2.911_{(227) ;} p=.004\right)$. En cuanto a la población peruana, se encontraron diferencias sólo en la satisfacción con la salud $\left(f=2.491_{(189,532) ;} p=.014\right)$, donde la media de los hombres es mayor que la de las mujeres. El efecto de la interacción entre sexo y nacionalidad no es significativo. La distribución de los participantes según sexo y país puede ser observada en la tabla 7.

Al evaluar la relación entre los puntajes obtenidos en las distintas dimensiones con la variable edad, se encuentra a 
Tabla 3. Caracterización de los participantes según país.

\begin{tabular}{|c|c|c|c|c|c|c|}
\hline & \multicolumn{2}{|c|}{$\mathrm{PE}$} & \multicolumn{2}{|c|}{$\mathrm{COL}$} & \multicolumn{2}{|c|}{ Total } \\
\hline & $\mathrm{n}$ & $\%$ & $\mathrm{n}$ & $\%$ & $\mathrm{n}$ & $\%$ \\
\hline \multicolumn{7}{|l|}{ Actividad económica } \\
\hline Activo/a, trabajador/a & 150 & 75.10 & 177 & 77.30 & 327 & 76.40 \\
\hline Jubilado/a, pensionado & 1 & 0.50 & 1 & 0.40 & 2 & 0.50 \\
\hline Cesante, buscando trabajo & 12 & 6.00 & 24 & 10.50 & 36 & 8.40 \\
\hline Ama de casa & 19 & 9.50 & 13 & 5.70 & 32 & 7.50 \\
\hline Estudiante & 4 & 2.00 & 6 & 2.60 & 10 & 2.30 \\
\hline No sabe / No contesta & 13 & 6.50 & 8 & 3.50 & 21 & 4.90 \\
\hline \multicolumn{7}{|l|}{ Ingreso mensual } \\
\hline Menos de $\$ 100.000$ & 11 & 5.60 & 13 & 5.70 & 24 & 5.60 \\
\hline Entre $\$ 100.000$ y $\$ 300.000$ & 87 & 44.40 & 111 & 48.50 & 198 & 46.60 \\
\hline Entre $\$ 300.000$ y $\$ 600.000$ & 76 & 38.80 & 71 & 31.00 & 147 & 34.60 \\
\hline Entre $\$ 600.000$ y $\$ 1.000 .000$ & 15 & 7.70 & 25 & 10.90 & 40 & 9.40 \\
\hline Entre $\$ 1.000 .000$ y $\$ 1.500 .000$ & 5 & 2.60 & 8 & 3.50 & 13 & 3.10 \\
\hline Más de $\$ 1.500 .000$ & 2 & 1.00 & 1 & 0.40 & 3 & 0.70 \\
\hline \multicolumn{7}{|l|}{ Situación administrativa-legal } \\
\hline Con permiso de residencia & 134 & 67.30 & 184 & 79.30 & 318 & 73.80 \\
\hline Sin permiso de residencia & 38 & 19.10 & 41 & 17.70 & 79 & 18.0 \\
\hline Nacionalizado & 26 & 13.10 & 7 & 3.00 & 33 & 7.70 \\
\hline No sabe / No contesta & 1 & 0.50 & - & - & 1 & 0.20 \\
\hline \multicolumn{7}{|l|}{ Permanencia en Chile } \\
\hline Menos de un año & 31 & 15.74 & 28 & 12.12 & 59 & 13.8 \\
\hline Entre un año y 3 años & 81 & 41.11 & 159 & 68.83 & 240 & 56.07 \\
\hline Entre 4 y 5 años & 31 & 15.74 & 32 & 13.85 & 85 & 14.71 \\
\hline Más de 5 años & 52 & 26.39 & 12 & 5.19 & 64 & 14.95 \\
\hline
\end{tabular}

Nota: PE: población peruana; COL: población colombiana. 
Tabla 4. Caracterización de las relaciones sociales de los participantes según país.

\begin{tabular}{|c|c|c|c|c|c|c|}
\hline & \multicolumn{2}{|c|}{ PE } & \multicolumn{2}{|c|}{$\mathrm{COL}$} & \multicolumn{2}{|c|}{ Total } \\
\hline & $\mathrm{n}$ & $\%$ & $\mathrm{n}$ & $\%$ & $\mathrm{n}$ & $\%$ \\
\hline Tiene pareja & 121 & 60.80 & 152 & 65.50 & 273 & 63.30 \\
\hline \multicolumn{7}{|l|}{ ¿Con quién vive? } \\
\hline Solo & 39 & 19.60 & 42 & 18.20 & 81 & 18.80 \\
\hline Con pareja & 72 & 36.20 & 90 & 39.00 & 162 & 37.70 \\
\hline Con amigos & 19 & 9.50 & 32 & 13.90 & 51 & 11.90 \\
\hline Con familiars & 63 & 31.70 & 66 & 28.60 & 129 & 30.00 \\
\hline Otros & 6 & 3.00 & 1 & 0.40 & 7 & 1.60 \\
\hline \multicolumn{7}{|l|}{ Contacto con población chilena: } \\
\hline $\begin{array}{l}\text { Ningún contacto. Sólo los ve en las calles o en lugares públicos, pero } \\
\text { nunca habla con ellos. }\end{array}$ & 14 & 7.20 & 12 & 5.30 & 26 & 6.20 \\
\hline $\begin{array}{l}\text { Los ve a menudo por cuestiones de vecindad, trabajo o estudios. No } \\
\text { les habla a menos que se dirijan a usted. }\end{array}$ & 40 & 20.60 & 51 & 22.50 & 91 & 21.60 \\
\hline $\begin{array}{l}\text { Los ve a menudo por cuestiones de vecindad, trabajo o estudios y se } \\
\text { relaciona frecuentemente con ellos. }\end{array}$ & 26 & 23.70 & 68 & 30.00 & 114 & 27.10 \\
\hline Tiene amigos de ese grupo. & 56 & 28.90 & 81 & 35.70 & 137 & 32.50 \\
\hline Tiene parientes de ese grupo. & 38 & 19.60 & 15 & 6.60 & 53 & 12.60 \\
\hline \multicolumn{7}{|l|}{ Contacto con población del país de origen. } \\
\hline $\begin{array}{l}\text { Ningún contacto. Sólo los ve en las calles o en lugares públicos, pero } \\
\text { nunca habla con ellos. }\end{array}$ & 9 & 4.70 & 7 & 3.10 & 16 & 3.80 \\
\hline $\begin{array}{l}\text { Los ve a menudo por cuestiones de vecindad, trabajo o estudios. No } \\
\text { les habla a menos que se dirijan a usted. }\end{array}$ & 18 & 9.30 & 19 & 8.40 & 37 & 8.80 \\
\hline $\begin{array}{l}\text { Los ve a menudo por cuestiones de vecindad, trabajo o estudios y se } \\
\text { relaciona frecuentemente con ellos. }\end{array}$ & 22 & 11.40 & 34 & 15.00 & 56 & 13.30 \\
\hline Tiene amigos de ese grupo. & 33 & 17.10 & 75 & 33.00 & 108 & 25.70 \\
\hline Tiene parientes de ese grupo. & 111 & 57.50 & 92 & 40.50 & 203 & 48.30 \\
\hline
\end{tabular}

Nota: PE: población peruana; COL: población colombiana.

Tabla 5. Autopercepción de fenotipo.

\begin{tabular}{|c|c|c|c|c|c|c|}
\hline \multirow{2}{*}{ Autodefinición fenotípica } & \multicolumn{2}{|c|}{$\mathrm{PE}$} & \multicolumn{2}{|c|}{$\mathrm{COL}$} & \multicolumn{2}{|c|}{ Total } \\
\hline & $\mathrm{N}$ & $\%$ & $\mathrm{n}$ & $\%$ & $\mathrm{n}$ & $\%$ \\
\hline Blanco/caucásico & 20 & 10,1 & 72 & 31,4 & 92 & 21,5 \\
\hline Pueblos indígenas & 48 & 24,1 & 6 & 2,6 & 54 & 12,6 \\
\hline Mestizo & 83 & 41,7 & 47 & 20,5 & 130 & 30,4 \\
\hline Negro & 8 & 4 & 48 & 21,0 & 56 & 13,1 \\
\hline Mulato & 28 & 14,1 & 51 & 22,3 & 79 & 18,5 \\
\hline
\end{tabular}

Nota: PE: población peruana; COL: población colombiana. 
Tabla 6. Resultados descriptivos sobre variables de calidad de vida total de participantes

\begin{tabular}{lcccccc}
\hline & \multicolumn{2}{c}{ Hombres } & \multicolumn{2}{c}{ Mujeres } & & Total \\
& M & DE & M & DE & M & DE \\
\hline CV General & 3.34 & 0.71 & 3.43 & 0.76 & 3.39 & 0.74 \\
Satisfacción con la salud & 3.27 & 0.94 & 3.02 & 0.90 & 3.14 & 0.93 \\
D. Físico & 14.93 & 2.30 & 14.26 & 2.31 & 14.58 & 2.33 \\
D. Psicológico & 14.52 & 2.38 & 13.98 & 2.36 & 14.24 & 2.39 \\
D. Social & 13.56 & 3.11 & 13.43 & 3.32 & 13.49 & 3.22 \\
D. Ambiental & 11.86 & 2.20 & 11.92 & 2.11 & 11.89 & 2.16 \\
\hline
\end{tabular}

Tabla 7. Resultados descriptivos sobre variables de calidad de vida.

\begin{tabular}{|c|c|c|c|c|c|c|c|c|c|c|c|c|}
\hline & \multicolumn{6}{|c|}{$\mathrm{COL}$} & \multicolumn{6}{|c|}{$\mathrm{PE}$} \\
\hline & \multicolumn{2}{|c|}{ Hombres } & \multicolumn{2}{|c|}{ Mujeres } & \multicolumn{2}{|c|}{ Total } & \multicolumn{2}{|c|}{ Hombres } & \multicolumn{2}{|c|}{ Mujeres } & \multicolumn{2}{|c|}{ Total } \\
\hline & M & $\mathrm{DE}$ & M & $\mathrm{DE}$ & M & $\mathrm{DE}$ & M & $\mathrm{DE}$ & M & $\mathrm{DE}$ & M & $\mathrm{DE}$ \\
\hline CV General & 3.36 & 0.78 & 3.49 & 0.85 & 3.42 & 0.82 & 3.31 & 0.62 & 3.36 & 0.65 & 3.34 & 0.64 \\
\hline Sat. con la salud & 3.23 & 1.02 & 3.00 & 1.02 & 3.12 & 1.02 & 3.31 & 0.85 & 3.03 & 0.75 & 3.17 & 0.81 \\
\hline D. Físico & 15.41 & 2.41 & 14.47 & 2.47 & 14.92 & 2.48 & 14.38 & 2.06 & 14.03 & 2.12 & 14.20 & 2.09 \\
\hline D. Psicológico & 14.93 & 2.56 & 14.35 & 2.61 & 14.63 & 2.60 & 14.04 & 2.08 & 13.55 & 1.97 & 13.79 & 2.04 \\
\hline D. Social & 14.06 & 3.41 & 14.18 & 3.50 & 14.13 & 3.45 & 12.98 & 2.63 & 12.55 & 2.87 & 12.76 & 2.76 \\
\hline D. Ambiental & 11.91 & 2.50 & 11.96 & 2.38 & 11.93 & 2.44 & 11.80 & 1.82 & 11.88 & 1.77 & 11.84 & 1.79 \\
\hline
\end{tabular}

PE: población peruana; COL: población colombiana.

Tabla 8. Medias en CV según autopercepción de fenotipo

\begin{tabular}{|c|c|c|c|c|c|c|c|c|c|c|}
\hline & \multicolumn{2}{|c|}{ Blanco } & \multicolumn{2}{|c|}{ Indígena } & \multicolumn{2}{|c|}{ Mestizo } & \multicolumn{2}{|c|}{ Negro } & \multicolumn{2}{|c|}{ Mulato } \\
\hline & M & $\mathrm{DE}$ & M & $\mathrm{DE}$ & M & $\mathrm{DE}$ & M & $\mathrm{DE}$ & M & $\mathrm{DE}$ \\
\hline \multicolumn{11}{|l|}{ Población general } \\
\hline CV general & 3.58 & 0.79 & 3.15 & 0.66 & 3.38 & 0.69 & 3.34 & 0.69 & 3.38 & 0.79 \\
\hline Satisfacción con la salud & 3.14 & 1.01 & 2.94 & 0.60 & 3.16 & 0.98 & 3.13 & 0.95 & 3.24 & 0.89 \\
\hline D. Físico & 14.76 & 2.37 & 13.54 & 2.24 & 14.58 & 2.20 & 14.63 & 2.22 & 15.19 & 2.49 \\
\hline D. Psicológico & 14.66 & 2.24 & 13.28 & 1.76 & 14.12 & 2.50 & 14.64 & 2.64 & 14.38 & 2.39 \\
\hline D. Social & 14.51 & 3.26 & 12.07 & 2.67 & 13.49 & 2.47 & 13. 29 & 3.93 & 13.81 & 3.35 \\
\hline D. Ambiental & 12.08 & 2.45 & 11.25 & 2.18 & 11.81 & 2.04 & 11.73 & 2.10 & 12.25 & 2.03 \\
\hline \multicolumn{11}{|l|}{ Pob. colombiana } \\
\hline CV general & 3.61 & 0.78 & 2.67 & 0.52 & 3.49 & 0.83 & 3.27 & 0.71 & 3.33 & 0.86 \\
\hline Satisfacción con la salud & 3.18 & 1.09 & 2.50 & 0.55 & 3.09 & 1.12 & 3.06 & 1.00 & 3.18 & 0.87 \\
\hline D. Físico & 14.82 & 2.48 & 13.17 & 1.83 & 15.34 & 2.23 & 14.60 & 2.35 & 15.31 & 2.92 \\
\hline D. Psicológico & 14.88 & 2.25 & 13.33 & 2.88 & 14.45 & 2.87 & 14.56 & 2.72 & 14.64 & 2.63 \\
\hline D. Social & 14.76 & 3.29 & 14.17 & 2.48 & 14.19 & 2.12 & 13.25 & 4.12 & 14.18 & 3.61 \\
\hline D. Ambiental & 12.07 & 2.56 & 10.33 & 3.20 & 11.80 & 2.46 & 11.63 & 2.14 & 12.27 & 2.38 \\
\hline \multicolumn{11}{|l|}{ Pob. peruana } \\
\hline CV general & 3.45 & 0.83 & 3.21 & 0.65 & 3.31 & 0.58 & 3.75 & 0.46 & 3.46 & 0.71 \\
\hline Sat. con la salud & 3.00 & 0.65 & 3.00 & 0.58 & 3.20 & 0.89 & 3.50 & 0.53 & 3.36 & 0.95 \\
\hline D. Físico & 14.55 & 1.99 & 13.58 & 2.30 & 14.14 & 2.08 & 14.75 & 1.28 & 15.00 & 1.47 \\
\hline D. Psicológico & 13.90 & 2.10 & 13.27 & 1.62 & 13.93 & 2.27 & 15.13 & 2.17 & 13.89 & 1.80 \\
\hline D. Social & 13.60 & 3.05 & 11.81 & 2.60 & 13.09 & 2.58 & 13.50 & 2.73 & 13.14 & 2.76 \\
\hline D. Ambiental & 12.11 & 2.02 & 11.37 & 2.03 & 11.82 & 1.78 & 12.38 & 1.85 & 12.21 & 1.17 \\
\hline
\end{tabular}


nivel de la muestra total que existen correlaciones inversas y estadísticamente significativas de ésta con los puntajes obtenidos en los dominios ambiental $(r=-.137 ; p=.005)$, social $(r=-.115 ; p=.018)$, psicológico $(r=-.181 ; p=.000)$, satisfacción con la salud $(r=-.102 ; p=.034)$ y calidad de vida general $(r=, 115 ; p=.017)$, donde a mayor edad, menor es el puntaje en las variables señaladas.

Al dividir la población por nacionalidad podemos observar que en la población colombiana la edad sólo se correlaciona con el dominio psicológico $(r=-.149 ; p=.024)$, ya que a mayor edad es menor la calidad de vida psicológica. En cuanto a la población peruana, la edad se correlacionó con la satisfacción con la salud ( $r=-.141 ; p=.047)$, calidad de vida física $(r=-.176 ; p=.013)$, calidad de vida psicológica $(r=-.204 ; p=.004)$ y calidad de vida ambiental $(r=-.173$; $p=.016$ ), donde a mayor edad menor es la CV percibida en los dominios mencionados.

Al analizar la existencia de diferencias de medias dado el nivel de estudio de los participantes, no se encontraron diferencias estadísticamente significativas ni en la $\mathrm{CV}$ general ni en los dominios evaluados.

Al analizar si existen diferencias de medias en los dominios de CV dada la autodefinición fenotípica (tabla 8), en la muestra total se encontró que existen diferencias estadísticamente significativas en los dominios físico $\left(F=2.952_{(6 ; 418) ;} p=.008\right)$, donde el grupo blanco/caucasiano presenta una media significativamente mayor que el grupo de pueblos indígenas ( $p=.044)$, y a su vez el grupo de pueblos indígenas tiene una media significativamente menor que el grupo mulato $(p=.001)$; dominio psicológico $\left(F=2.48_{(6 ; 419) ;}\right.$ $p=.022$ ), donde el grupo de blanco/caucasiano presenta la media significativamente mayor que el grupo de pueblos indígenas $(p=.014)$ y $\operatorname{Social}\left(F=4.609_{(6 ; 418)} p=.000\right)$, donde el grupo blanco/caucasiano presenta una media significativamente mayor que la media del grupo de pueblos indígenas $(p=.000)$; a su vez, el grupo de pueblos indígena presenta una media significativamente menor que la media del grupo mestizo $(p=.020)$ y mulato $(p=.021)$.

$\mathrm{Al}$ analizar la autodefinición fenotípica con los dominios de calidad de vida según la nacionalidad de los participantes, se observó que en la población colombiana y peruana no existen diferencias de medias estadísticamente significativas.

\section{Calidad de vida y variables socio-económicas}

Al analizar si existen diferencias de medias en los dominios de CV dada la actividad económica, se encontró que en la muestra total existen diferencias estadísticamente significativas en la CV general $\left(t=-2.279_{(58,578)} p=.026\right)$, donde la media de la categoría ama de casa es mayor a la de los cesantes/buscando trabajo. También se encontraron diferencias en el dominio psicológico, donde la media de los activos/trabajador por cuenta propia o ajena y estudiantes son mayores que la de la categoría cesantes/buscando trabajo $\left(t=2.541_{(36) ;} p=.011\right.$ y $t=-2.018_{(44) ;} p=.050$, respectivamente). También existen diferencias estadísticamente significativas en el dominio social $\left(t=2.031_{(358) ;} p=.043\right)$, donde la media del grupo activo/trabajador por cuenta propia o ajena es mayor que la del grupo cesante/buscando trabajo.

Al estratificar el análisis por nacionalidad, encontramos que en la población colombiana existen diferencias estadísticamente significativas en la CV general, donde la media del grupo ama de casa es mayor a la de los cesantes/ buscando trabajo ( $\left.t=-2.829_{(35):} p=.008\right)$; en el dominio físico, donde la media del grupo activo/trabajador por cuenta propia o ajena es mayor que la del grupo ama de casa $\left(t=2.033_{(185) ;} p=.043\right)$ y en el dominio social en donde la media del grupo cesante buscando trabajo es menor que la del grupo activo/trabajador por cuenta propia o ajena $\left(t=2.518_{(197) ;} p=.013\right)$. Sobre la población peruana se encontró una diferencia de medias estadísticamente significativa sólo en el dominio psicológico, donde la media del grupo cesante/ buscando trabajo es menor que la del grupo activo/trabajador por cuenta propia o ajena $\left(t=2.259_{(160)} p=.025\right)$, y que la del grupo estudiante $\left(t=-2.675_{(14) ;} p=.018\right)$.

$\mathrm{Al}$ analizar las dimensiones de calidad de vida y el ingreso mensual de los participantes (tabla 9), se hallaron diferencias estadísticamente significativas en todos los dominios.

En el dominio ambiental $\left(F=4.832_{(5,410) ;} p=.000\right)$, la media del grupo que gana entre 600 mil y 1.000 .000 es significativamente mayor a la del grupo que gana entre 100 y $300 \mathrm{mil}(p=.017)$. En tanto, la media del grupo que gana menos de 100 mil es significativamente menor a la de los grupos que ganan entre 300 y $600 \mathrm{mil}(p=.018), 600 \mathrm{mil}$ y $1.000 .000(p=.001)$ entre 1.000 .000 y $1.500 .000(p=.030)$. Por otra parte, la media del grupo que gana entre $100 \mathrm{y}$ 300 mil es significativamente menor a la de los grupos que ganan entre 300 y 600 mil ( $p=.006)$, y de la media de los que ganan entre 600 mil y $1.000 .000(p=.000)$. Por último, la media del grupo que gana entre 600 mil y 1.000 .000 es significativamente mayor a la del grupo que gana entre 300 mil y 600 mil $(p=.035)$.

En el dominio social $\left(F=3.840_{(5,416) ;} p=.002\right)$, la media del grupo que gana entre 100 y 300 mil es significativamente menor a la de los grupos que ganan entre 300 y 600 mil $(p=.006), 600$ mil y $1.000 .000(p=.006)$, y 600 mil y $1.000 .000(p=.000)$. 
Tabla 9. Medias en dimensiones de CV por rango de ingreso mensual muestra total

\begin{tabular}{|c|c|c|c|c|c|c|c|c|c|c|c|c|}
\hline & \multicolumn{12}{|c|}{ Rango de ingresos } \\
\hline & \multicolumn{2}{|c|}{1} & \multicolumn{2}{|c|}{2} & \multicolumn{2}{|c|}{3} & \multicolumn{2}{|c|}{4} & \multicolumn{2}{|c|}{5} & \multicolumn{2}{|c|}{6} \\
\hline & M & $\mathrm{DE}$ & M & $\mathrm{DE}$ & M & $\mathrm{DE}$ & M & DE & M & $\mathrm{DE}$ & $\mathrm{M}$ & $\mathrm{DE}$ \\
\hline CV General & 3.25 & 0.79 & 3.31 & 0.67 & 3.42 & 0.73 & 3.57 & 0.90 & 3.69 & 0.75 & 3.33 & 0.57 \\
\hline D. Físico & 13.66 & 2.27 & 14.14 & 2.22 & 14.93 & 2.27 & 15.70 & 2.26 & 15.15 & 2.96 & 17.00 & 1.73 \\
\hline D. Psic. & 13.66 & 2.47 & 13.92 & 2.37 & 14.37 & 2.29 & 14.92 & 2.64 & 15.76 & 1.64 & 16.00 & 3.60 \\
\hline D. Ambient. & 11.04 & 2.61 & 11.51 & 1.91 & 12.14 & 2.08 & 12.94 & 2.51 & 12.61 & 2.06 & 12.66 & 4.04 \\
\hline D. Social & 12.66 & 3.01 & 12.91 & 3.41 & 13.86 & 2.97 & 14.87 & 2.79 & 14.46 & 2.87 & 14.33 & 2.08 \\
\hline
\end{tabular}

$1=$ Menos de $\$ 100.000 ; 2=$ Entre $\$ 100.000$ y $\$ 300.000 ; 3=$ Entre $\$ 300.000$ y $\$ 600.000 ; 4=$ Entre $\$ 600.000$ y $\$ 1.000 .000 ; 5=$ Entre $\$ 1.000 .000$ y $\$ 1.500 .000$; $6=$ Más de $\$ 1.500 .000$

Tabla 10. Dimensiones de CV por rango de ingreso mensual por país.

\begin{tabular}{|c|c|c|c|c|c|c|c|c|c|c|c|c|}
\hline & \multicolumn{12}{|c|}{ Nivel de ingresos } \\
\hline & \multicolumn{2}{|c|}{1} & \multicolumn{2}{|c|}{2} & \multicolumn{2}{|c|}{3} & \multicolumn{2}{|c|}{4} & \multicolumn{2}{|c|}{5} & \multicolumn{2}{|c|}{6} \\
\hline & M & $\mathrm{DE}$ & M & $\mathrm{DE}$ & M & $\mathrm{DE}$ & M & $\mathrm{DE}$ & M & $\mathrm{DE}$ & M & $\mathrm{DE}$ \\
\hline \multicolumn{13}{|l|}{ COLOMBIA } \\
\hline Físico & 13.46 & 2.33 & 13.50 & 2.29 & 15.39 & 2.42 & 16.04 & 2.49 & 15.25 & 3.37 & 18.00 & 0.0 \\
\hline Psicológico & 14.23 & 2.97 & 14.27 & 2.53 & 14.85 & 2.46 & 15.16 & 3.13 & 15.37 & 1.76 & 19.00 & 0.0 \\
\hline Social & 13.54 & 3.78 & 13.40 & 3.70 & 14.73 & 2.93 & 15.44 & 2.96 & 14.88 & 3.44 & 12.00 & 0.0 \\
\hline Ambiental & 11.54 & 2.79 & 11.48 & 2.13 & 12.10 & 2.36 & 13.29 & 3.03 & 12.50 & 2.62 & 12.00 & 0.0 \\
\hline \multicolumn{13}{|l|}{ PERÚ } \\
\hline Físico & 13.91 & 2.30 & 13.69 & 2.05 & 14.51 & 2.06 & 15.13 & 1.77 & 15.00 & 2.55 & 16.50 & 2.12 \\
\hline Psicológico & 13.00 & 1.61 & 13.47 & 2.07 & 13.92 & 2.03 & 14.53 & 1.55 & 16.40 & 1.34 & 14.50 & 3.54 \\
\hline Social & 11.63 & 1.28 & 12.29 & 2.90 & 13.06 & 2.81 & 13.93 & 2.28 & 13.80 & 1.78 & 15.50 & 0.70 \\
\hline Ambiental & 10.45 & 2.38 & 11.55 & 1.61 & 12.19 & 1.81 & 12.40 & 1.24 & 12.80 & 0.84 & 13.00 & 5.66 \\
\hline
\end{tabular}

$1=$ Menos de $\$ 100.000 ; 2=$ Entre $\$ 100.000$ y $\$ 300.000 ; 3=$ Entre $\$ 300.000$ y $\$ 600.000 ; 4=$ Entre $\$ 600.000$ y $\$ 1.000 .000 ; 5=$ Entre $\$ 1.000 .000$ y $\$ 1.500 .000$; $6=$ Más de $\$ 1.500 .000$.

En el dominio psicológico $\left(F=3.166_{(5,418) ;} p=.008\right)$, la media de los que ganan entre 1.000 .000 y 1.500 .000 es significativamente más alta que los grupos que ganan menos de 100 mil $(p=.010)$ y entre 100 y 300 mil $(p=.007)$, y los que ganan entre 300 mil y $600 \mathrm{mil}$ ( $p=.042$ ). Por otro lado, las medias del grupo que gana entre 600 mil y 1.000 .000 son significativamente más altas que quienes ganan menos de 100 mil $(p=.040)$ y entre 100 y 300 mil $(p=.015)$.

En el dominio físico $\left(f=5.722_{(5,416) ;} p=.000\right)$, la media del grupo que gana más de 1.500 .000 es significativamente mayor a las medias de los grupos que ganan menos de $100 \mathrm{mil}(p=.017)$ y entre $100 \mathrm{mil} \mathrm{y} 300 \mathrm{mil}(p=.031)$. En tanto, la media del grupo que gana menos de 100 mil es significativamente menor a la del grupo que gana entre 600 mil y $1.000 .000(p=.009)$, asimismo, la media del grupo que gana entre 100 mil y 300 mil es significativamente menor a la del grupo que gana entre 300 mil y
600 mil $(p=.024)$ y del grupo que gana entre 600 mil y $1.000 .000(p=.001)$.

$\mathrm{Al}$ analizar la muestra por nacionalidad (tabla 10), en la población colombiana se presentaron diferencias estadísticamente significativas en los dominios físico $\left(f=3.593_{(5,220)} ; p=.004\right)$, social $\left(f=2.421_{(5,221) ;} p=.037\right)$ y ambiental $\left(f=2.593_{(5,218) \text {; }}\right.$ $p=.027$ ), donde la media del grupo que gana entre $\$ 600.000 \mathrm{y}$ $\$ 1.000 .000$ es significativamente mayor a la de los otros grupos.

En cuanto a la población peruana, igualmente se hallaron diferencias estadísticamente significativas en los dominios físico $\left(f=2.720_{(5,223)} ; p=.021\right)$, donde la media del grupo que gana más de $\$ 1.500 .000$ es significativamente mayor a la de los otros grupos, psicológico $\left(f=3.037_{(5,189) ;} p=.12\right)$, donde la media del grupo que gana menos de 100 mil es menor a la del grupo que gana entre 1.000 .000 y 1.500 .000 $(p=.002)$, asimismo, la media del grupo que gana entre 100 mil y 300 mil es menor a la de los que ganan entre 
1.000 .000 y $1.500 .000(p=.002)$, y la media de los que ganan entre 300 mil y 600 mil es menor a la del grupo que gana entre 1.000 .000 y $1.500 .000(p=.008)$, y en el dominio ambiental $\left(f=3.210_{(5,186) ;} p=.008\right)$, donde la media de quienes ganan entre 300 y 600 mil es estadísticamente superior a quienes ganan menos de 100 mil.

Con respecto a las diferencias de medias en los dominios de calidad de vida y la situación administrativa o legal (con permiso de residencia/sin permiso de residencia) de los evaluados (Tabla 11), a nivel de la población en general se encontraron diferencias estadísticamente significativas en la CV general ( $\left.t=2.695_{(395) ;} p=.007\right)$, en el dominio psicológico $\left(t=3.203_{(393) ;} p=.001\right)$, ambiental $\left(t=2.727_{(387) \text {; }}\right.$ $p=.007)$, físico $\left(t=1.972_{(392) ;} p=.049\right)$ y social $\left(t=2.342_{(393) ;}\right.$ $p=.020)$. En todas éstas, las medias de las personas que se encuentran con residencia son mayores a la media del grupo que está sin permiso de residencia.

Al estratificar el análisis por nacionalidad, en la población colombiana se encontraron diferencias estadísticamente significativas en la CV general $\left(t=2.368_{(223) ;} p=.019\right)$, en el dominio psicológico $\left(t=2.288_{(222) ;} \mathrm{p}=0.023\right)$, social $(t=2.750$ (221); $p=.006)$ y ambiental $\left(t=2.370_{(218) ;} p=.019\right)$, presentando en todos los casos una media mayor en el grupo de personas con permiso de residencia.

En la población peruana las diferencias se encontraron sólo en el psicológico $\left(t=2.089_{(169) ;} p=.038\right)$, con una media mayor en el grupo de las personas con permiso de residencia que las que manifiestan encontrarse sin permiso de residencia

No se encontró relación entre los puntajes de las medias de los dominios de $\mathrm{CV}$ y los años de permanencia en la muestra total, sin embargo, al dividir el grupo por nacionalidad, en la población peruana la permanencia se correlaciona con la satisfacción con la salud, donde a mayor estadía en la ciudad mejores niveles de satisfacción en la salud $(r=.154 ; p=.032)$.

\section{Calidad de vida y variables relacionales}

A nivel de muestra general, al analizar si existen diferencias de medias en los puntajes de $\mathrm{CV}$ dependiendo si se tiene o no pareja (tabla 12), se encontraron diferencias estadísticamente significativas en la CV general $\left(t=2.148_{(429) ;}\right.$ $p=.032)$, en el dominio psicológico $\left(t=2.606_{(427) ;} p=.009\right) \mathrm{y}$ social $\left(t=5.066_{(426)} ; p=.000\right)$. En todas éstas, las medias de las personas que están en pareja son mayores.

Tabla 11. Resultados descriptivos de variables de calidad de vida según situación de extranjería.

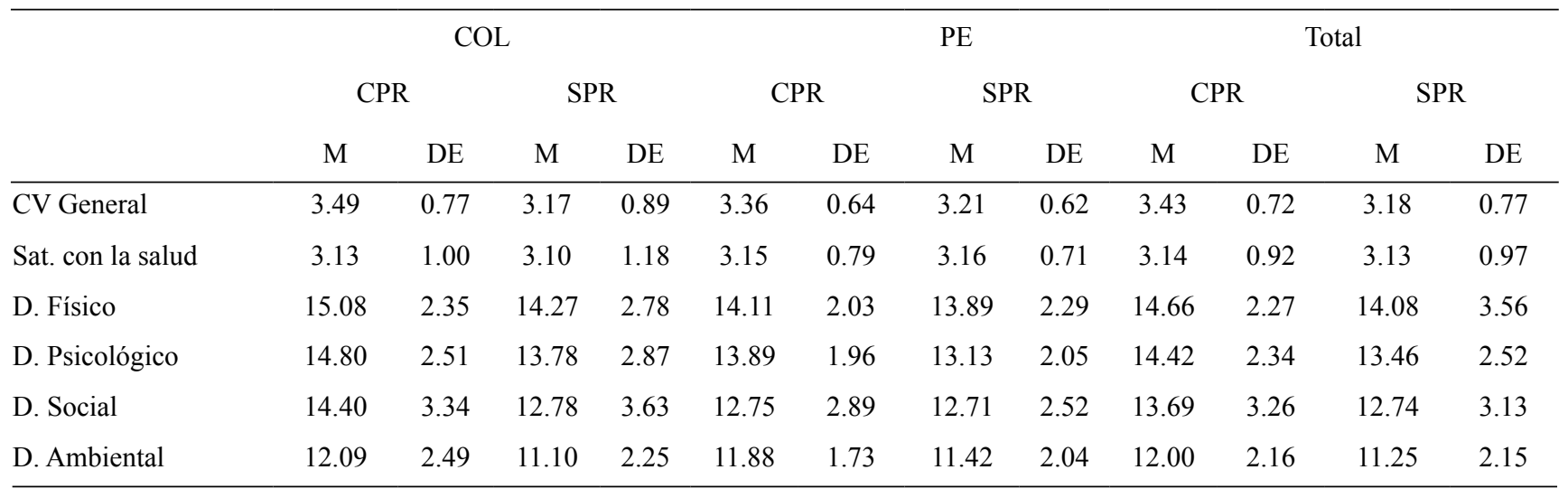

PE: población peruana; COL: población colombiana; CPR: con permiso de residencia; SPR: sin permiso de residencia.

Tabla 12. Medias de CV según estado de pareja.

\begin{tabular}{lcccccccccccc}
\hline & \multicolumn{4}{c}{ COLOMBIA } & \multicolumn{4}{c}{ PERÚ } & \multicolumn{4}{c}{ TOTAL } \\
& \multicolumn{1}{c}{ Tiene pareja } & \multicolumn{2}{c}{ No tiene pareja } & \multicolumn{2}{c}{ Tiene pareja } & \multicolumn{2}{c}{ No tiene pareja } & \multicolumn{2}{c}{ Tiene pareja } & \multicolumn{2}{c}{ No tiene pareja } \\
& M & DE & M & DE & M & DE & M & DE & M & DE & M & DE \\
\hline CV general & 3.53 & 0.81 & 3.24 & 0.82 & 3.34 & 0.65 & 3.33 & 0.62 & 3.44 & 0.75 & 3.29 & 0.72 \\
Físico & 15.05 & 2.40 & 14.66 & 2.62 & 14.19 & 2.01 & 14.21 & 2.24 & 14.67 & 2.27 & 14.43 & 2.44 \\
Psic. & 14.90 & 2.44 & 14.10 & 2.80 & 13.92 & 2.02 & 13.59 & 2.07 & 14.47 & 2.31 & 13.85 & 2.47 \\
Soc. & 14.56 & 3.12 & 13.28 & 3.91 & 13.46 & 2.54 & 11.68 & 2.75 & 14.07 & 2.92 & 12.48 & 3.46 \\
Amb. & 12.16 & 2.38 & 11.49 & 2.49 & 11.89 & 1.66 & 11.76 & 1.99 & 12.04 & 2.10 & 11.63 & 2.25 \\
\hline
\end{tabular}


Tabla 13. Medias en CV según con quién vive, muestra total.

\begin{tabular}{lcccccccccccccc}
\hline Dimensión CV & \multicolumn{10}{c}{ ¿Con quién vive?-Población general } \\
& \multicolumn{2}{c}{ Solo } & \multicolumn{1}{c}{ Pareja } & \multicolumn{1}{c}{ Amigos } & \multicolumn{1}{c}{ Familiares } & \multicolumn{1}{c}{ Otros } & \multicolumn{4}{c}{ Total } \\
& M & DE & M & DE & M & DE & M & DE & M & DE & M & DE \\
CV física & 13.85 & 0.79 & 14.77 & 0.78 & 15.08 & 0.79 & 14.64 & 0.68 & 14.00 & 0.63 & 3.39 & 0.74 \\
CV psicológica & 14.64 & 2.41 & 15.03 & 2.39 & 15.01 & 2.51 & 14.53 & 2.09 & 13.75 & 2.36 & 14.58 & 2.34 \\
CV social & 14.58 & 2.38 & 14.35 & 2.54 & 14.92 & 2.57 & 14.10 & 2.36 & 13.33 & 1.82 & 14.25 & 2.39 \\
CV ambiental & 14.38 & 3.52 & 13.64 & 3.38 & 13.76 & 3.77 & 13.36 & 2.58 & 12.52 & 2.91 & 13.52 & 3.19 \\
\hline
\end{tabular}

Tabla 14. Medias de CV según grado de contacto con población chilena.

Grado de contacto con personas chilenas (población peruana)

\begin{tabular}{|c|c|c|c|c|c|c|c|c|c|c|}
\hline & \multicolumn{2}{|c|}{1} & \multicolumn{2}{|c|}{2} & \multicolumn{2}{|c|}{3} & \multicolumn{2}{|c|}{4} & \multicolumn{2}{|c|}{5} \\
\hline & M & $\mathrm{DE}$ & M & $\mathrm{DE}$ & M & $\mathrm{DE}$ & M & $\mathrm{DE}$ & M & $\mathrm{DE}$ \\
\hline \multicolumn{11}{|l|}{$\mathrm{CV}$ general } \\
\hline $\mathrm{CV}$ fisica & 12.57 & 2.31 & 14.03 & 2.28 & 14.17 & 1.91 & 14.64 & 1.99 & 14.39 & 1.78 \\
\hline \multicolumn{11}{|l|}{ Cv psic. } \\
\hline $\mathrm{CV}$ social & 10.93 & 3.12 & 12.43 & 2.80 & 12.61 & 3.09 & 13.18 & 2.31 & 13.42 & 2.41 \\
\hline \multicolumn{11}{|l|}{ Cv ambiental } \\
\hline Satisfacción con la salud & 2.57 & 0.76 & 3.15 & 0.83 & 3.33 & 0.76 & 3.32 & 0.94 & 3.00 & 0.52 \\
\hline
\end{tabular}

$1=$ Ningún contacto, sólo las ve en las calles o lugares públicos; las ve a menudo pero nunca habla con ellas; 2 = Las ve a menudo por cuestiones de vecindad, trabajo o estudios, pero no les habla a menos que se dirijan a usted; $3=$ Las ve a menudo por cuestiones de vecindad, trabajo o estudios, y se relaciona frecuentemente con ellos; $4=$ Tiene amigos de ese grupo; $5=$ Tiene parientes en ese grupo.

Al analizar la muestra por nacionalidad, en la población colombiana se encontraron diferencias estadísticamente significativas en la CV general $\left(t=2.586_{(230) ;} p=.010\right) \mathrm{y}$ dimensión psicológica $\left(t=2.145_{(140,236) ;} p=.034\right)$ y social $\left(t=2.692_{(228)} p=.008\right)$, presentando medias más altas los grupos que expresaron estar con pareja. En cuanto a la población peruana, se encontraron diferencias estadísticamente significativas sólo en la dimensión social, presentando una media mayor el grupo que manifiesta tener pareja del que alude no tener pareja $\left(t=4.662,{ }_{(196) ;}\right.$ $p=.000)$.

$\mathrm{Al}$ analizar si existen diferencias en los puntajes de $\mathrm{CV}$ dadas por la variable ¿Con quién vive? (tabla 13), en la muestra total se encontraron diferencias estadísticamente significativas en las dimensiones física $\left(f=2.947_{(4,422) \text {; }}\right.$ $p=.020)$, donde la media del grupo que vive solo es significativamente más baja que los que viven con amigos $(p=.034)$ y con pareja $(p=.27)$. Existen también diferencias en el dominio psicológico $\left(f=7.626_{(4,423) ;} p=.000\right)$, donde la media del grupo que vive con amigos es significativamente más alta que los que viven solos ( $p=.000$ ) y en la dimensión social $\left(f=8.466_{(4,422) ;} p=.000\right)$, donde la media de los que viven con pareja es significativamente más alta que los que viven solos $(p=.000)$.

Al realizar el análisis por nacionalidad, se encontraron diferencias estadísticamente significativas en la población colombiana, en CV general $\left(f=3.307_{(4,226) ;} p=.012\right)$, donde la media del grupo que vive con familiares $(M=3.61)$ es significativamente mayor a la de los otros grupos, la dimensión psicológica $\left(f=4.985_{(4,225) ;} p=.001\right)$, donde la media del grupo que declara vivir con "otros" $(\mathrm{m}=16.00)$ es significativamente mayor a la de los otros grupos, y la dimensión social $\left(f=5.114_{(4,224)}, p=.001\right)$, donde la media del grupo que vive con "otros" $(M=15.00)$ es significativamente mayor a la de los otros grupos.

En la población peruana se encontraron diferencias en la dimensión psicológica $\left(f=2.733_{(4,193) ;} p=.030\right)$, donde la media del grupo que vive con amigos $(M=14.32)$ es significativamente más alta que en los otros grupos, y la dimensión social $\left(f=3.753_{(4,193) ;} p=.006\right)$, donde la media del grupo que 
vive con pareja $(m=13.5000)$ es significativamente mayor que en los otros grupos.

$\mathrm{Al}$ analizar las diferencias de medias en CV según el grado de contacto que mantienen los participantes con personas de Chile (Tabla 14), en la muestra general se encontraron diferencias estadísticamente significativas en el dominio físico $\left(f=2.455_{(4,413) ;} p=.045\right)$, donde la media del grupo que refiere tener amigos chilenos es significativamente mayor a la media del grupo que refiere verlos a menudo por cuestiones de vecindad, trabajo o estudios, y se relaciona frecuentemente con ellos ( $p=.041)$, y significativamente mayor a la del grupo que refiere no mantener ningún contacto (0.009). De igual forma, se encontraron diferencias significativas en el dominio social $\left(f=2.990_{(4,413) ;} p=.019\right)$, donde la media del grupo que señala tener amigos de ese grupo es significativamente mayor a la del grupo que refiere verlos a menudo por cuestiones de vecindad, trabajo o estudios, y no les habla a menos que se dirijan a ellos $(p=.022)$.

En los participantes peruanos se encontraron diferencias estadísticamente significativas en la dimensión física $\left(f=3.106_{(4,189) ;} p=.17\right)$, donde la media del grupo que no mantiene ningún contacto es menor a la media del grupo que expresa tener amigos de ese grupo $(p=.007)$ y parientes de ese grupo $(p=.044)$, y en el dominio social $\left(f=2.711_{(4,188)} p=.03\right)$, donde el grupo que refiere no mantener ningún contacto es menor a la media del grupo que dice tener parientes de ese grupo $(p=.035)$. En la satisfacción con la salud $(f=3.393$ $(4,189) ; p=.010)$, la media del grupo que refiere no mantener ningún contacto con personas chilenas es menor a la media del grupo que refiere verlos a menudo por cuestiones de vecindad, trabajo o estudios, y se relaciona frecuentemente con ellos $(p=.027)$, y del grupo que expresa tener amigos en ese grupo $(p=.032)$.

Por parte de la población colombiana sólo se hallaron diferencias significativas en la dimensión social $(f=2.478$ $(4,220) ; p=.045)$, donde la media del grupo que refiere tener amigos chilenos es mayor a la media del grupo que manifiesta tener parientes en ese grupo ( $p=.049)$, del grupo que los ve a menudo por cuestiones de vecindad, trabajo o estudios, $\mathrm{y}$ no les habla a menos que se dirijan a ellos $(p=.011)$, y de los que declaran verlos a menudo por cuestiones de vecindad, trabajo o estudios, y se relaciona frecuentemente con ellos $(p=.034)$. No se encontraron diferencias estadísticamente significativas en las otras dimensiones.

Con respecto al contacto que mantienen en Chile con personas de su misma nacionalidad, a nivel de la muestra total sólo se encontraron diferencias significativas en la satisfacción con la salud donde el grupo que las ve a menudo por cuestiones de vecindad, trabajo o estudios y se relaciona frecuentemente con ellas obtuvo una media mayor que el grupo que las ve a menudo por cuestiones de vecindad, trabajo o estudios, que no les habla a menos que se dirijan a usted ( $\left.t=-2.658_{(91)} p=.009\right)$, asimismo el grupo que tiene parientes de ese grupo obtuvo una media mayor que el que las ve a menudo por cuestiones de vecindad, trabajo o estudios $\left(t=-2.085_{(238) ;} p=.038\right)$.

$\mathrm{Al}$ analizar por nacionalidad, en la población colombiana se encontró que existen diferencias estadísticamente significativas en la satisfacción con la salud, donde el grupo que las ve a menudo por cuestiones de vecindad, trabajo o estudios y se relaciona frecuentemente con ellas obtuvo una media mayor que el grupo que las ve a menudo por cuestiones de vecindad, trabajo o estudios, pero no les habla a menos que se dirijan a usted $\left(t=-2.638_{(51) ;}=.011\right)$, y quienes escogieron la opción tiene amigos de ese grupo $\left(t=-2.059_{(91)} p=.042\right)$, a su vez este grupo obtuvo medias menores al grupo que las ve a menudo por cuestiones de vecindad, trabajo o estudios y se relaciona frecuentemente con ellos $\left(t=2.228_{(45,257) ;} p=.031\right)$.

En cuanto a la población peruana, se encontraron diferencias estadísticamente significativas en la satisfacción con la salud, donde los grupos las ve a menudo por cuestiones de vecindad, trabajo o estudios, pero no les habla a menos que se dirijan a usted ( $\left.t=-2.288_{(25):} p=.031\right)$, las ve a menudo por cuestiones de vecindad, trabajo o estudios y se relaciona frecuentemente con ellas ( $\left.t=-2.833_{(29) ;} p=.008\right)$, tiene amigos de ese grupo $\left(t=-2.615_{(40) ;} p=.013\right)$ y tiene parientes de ese grupo ( $\left.t=-3.350_{(118) ;} p=.001\right)$ obtuvieron medias mayores que el grupo ningún contacto. Sólo las ve en las calles o en lugares públicos, pero nunca habla con ellas.

En el dominio de calidad de vida física también se encontraron diferencias significativas, donde los grupos las ve a menudo por cuestiones de vecindad, trabajo o estudios, pero no les habla a menos que se dirijan a usted ( $\left.t=-3.391_{(25) ;} p=.002\right)$, las ve a menudo por cuestiones de vecindad, trabajo o estudios y se relaciona frecuentemente con ellas $\left(t=-2.106_{(29) ;} p=.044\right)$ y tiene parientes de ese grupo ( $\left.t=-3.131_{(118) ;} p=.002\right)$ obtuvieron medias mayores que el grupo ningún contacto. Sólo las ve en las calles o en lugares públicos, pero nunca habla con ellas. En tanto, el grupo Tiene amigos de ese grupo obtuvo una media menor que los grupos las ve a menudo por cuestiones de vecindad, trabajo o estudios, pero no les habla a menos que se dirijan a usted ( $\left.t=2.614_{(49):} p=.012\right)$ y tiene parientes de ese grupo $\left(t=-2.667_{(142) ;} p=.009\right)$.

En lo que respecta al dominio de calidad de vida psicológica, se encontraron diferencias significativas $\left(t=-2.720_{(142) ;} p=.007\right)$, donde el grupo tiene parientes 
Tabla 15. Coeficientes significativos de la recta de regresión por país, CV general.

\begin{tabular}{|c|c|c|c|c|c|c|}
\hline \multirow[t]{2}{*}{ CV General } & & \multicolumn{2}{|c|}{$\begin{array}{c}\text { Coeficientes } \\
\text { no estandarizados }\end{array}$} & \multirow{2}{*}{$\begin{array}{c}\text { Coeficientes } \\
\text { estandarizados } \\
\text { Beta }\end{array}$} & \multirow[t]{2}{*}{$\mathrm{t}$} & \multirow[t]{2}{*}{ Sig. } \\
\hline & & B & Error típ. & & & \\
\hline \multirow[t]{4}{*}{ Población total } & (Constante) & 3.628 & .243 & & 14.919 & .000 \\
\hline & Nivel de ingresos & .095 & .039 & .119 & 2.445 & .015 \\
\hline & Edad & -.011 & .004 & -.139 & -2.877 & .004 \\
\hline & ¿Usted vive con? & .070 & .031 & .111 & 2.290 & .023 \\
\hline \multirow[t]{3}{*}{ Población colombiana } & (Constante) & 3.817 & .382 & & 10.000 & .000 \\
\hline & Edad & -.012 & .006 & -.134 & -2.056 & .041 \\
\hline & ¿Usted vive con? & .133 & .048 & .181 & 2.771 & .006 \\
\hline
\end{tabular}

Tabla 16. Coeficientes significativos de la recta de regresión por país, CV física.

\begin{tabular}{|c|c|c|c|c|c|c|}
\hline \multirow[t]{2}{*}{ CV Física } & & \multicolumn{2}{|c|}{$\begin{array}{c}\text { Coeficientes } \\
\text { no estandarizados }\end{array}$} & \multirow{2}{*}{$\begin{array}{c}\text { Coeficientes } \\
\text { tipificados } \\
\text { Beta }\end{array}$} & \multirow[t]{2}{*}{$\mathrm{t}$} & \multirow[t]{2}{*}{ Sig. } \\
\hline & & B & Error típ. & & & \\
\hline \multirow[t]{3}{*}{ Población total } & (Constante) & 13.764 & .776 & & 17.727 & .000 \\
\hline & Nivel de ingresos & .591 & .124 & .229 & 4.756 & .000 \\
\hline & Edad & -.031 & .012 & -.126 & -2.640 & .009 \\
\hline \multirow[t]{2}{*}{ Población colombiana } & (Constante) & 14.394 & 1.203 & & 11.965 & .000 \\
\hline & Nivel de ingresos & .640 & .181 & .239 & 3.535 & .001 \\
\hline \multirow[t]{2}{*}{ Población peruana } & (Constante) & 12.676 & 1.020 & & 12.423 & .000 \\
\hline & Nivel de ingresos & .527 & .166 & .223 & 3.185 & .002 \\
\hline
\end{tabular}

Tabla 17. Coeficientes significativos de la recta de regresión.

\begin{tabular}{|c|c|c|c|c|c|c|}
\hline \multirow[t]{2}{*}{ CV Psicológica } & & \multicolumn{2}{|c|}{$\begin{array}{c}\text { Coeficientes } \\
\text { no estandarizados }\end{array}$} & \multirow{2}{*}{$\begin{array}{c}\text { Coeficientes } \\
\text { estandarizados } \\
\text { Beta }\end{array}$} & \multirow[t]{2}{*}{$\mathrm{t}$} & \multirow[t]{2}{*}{ Sig. } \\
\hline & & B & Error típ. & & & \\
\hline \multirow[t]{5}{*}{ Población total } & (Constante) & 15.387 & .780 & & 19.729 & .000 \\
\hline & Edad & -.047 & .012 & -.185 & -3.931 & .000 \\
\hline & Nivel de ingresos & .424 & .125 & .161 & 3.401 & .001 \\
\hline & ¿Tiene ud. pareja? & -.691 & .235 & -.139 & -2.946 & .003 \\
\hline & ¿Usted vive con? & .306 & .098 & .147 & 3.113 & .002 \\
\hline \multirow[t]{5}{*}{ Población colombiana } & (Constante) & 15.582 & 1.239 & & 12.580 & .000 \\
\hline & Edad & -.043 & .018 & -.152 & -2.346 & .020 \\
\hline & Nivel de ingresos & .414 & .187 & .147 & 2.218 & .028 \\
\hline & ¿Tiene ud. pareja? & -.729 & .358 & -.132 & -2.034 & .043 \\
\hline & ¿Usted vive con? & .438 & .156 & .183 & 2.809 & .005 \\
\hline \multirow[t]{3}{*}{ Población peruana } & (Constante) & 14.379 & .993 & & 14.475 & .000 \\
\hline & Edad & -.045 & .015 & -.214 & -3.010 & .003 \\
\hline & Nivel de ingresos & .472 & .161 & .205 & 2.926 & .004 \\
\hline
\end{tabular}


de ese grupo obtuvo una media mayor que el grupo tiene amigos de ese grupo.

Por último, en el dominio ambiental $\left(t=-2.584_{(140)}\right.$; $p=.011$ ), el grupo tiene amigos de ese grupo obtuvo una media menor que el grupo tiene parientes de ese grupo.

\section{Variables predictoras $C V$ general}

Al realizar el análisis considerando a todos los participantes de la muestra total, encontramos que son significativas al modelo las variables edad, nivel de ingresos y con quién vive, las cuales son capaces de explicar un $4.8 \%$ de la varianza de la variable $\mathrm{CV}$ general. Al estratificar el análisis por país, en la población colombiana se mantienen como variables predictoras la edad y con quién vive, aumentando la varianza explicada a un $7.8 \%$. En tanto, las variables introducidas en el modelo no fueron significativas para explicar la $\mathrm{CV}$ de la población peruana (tabla 15).

\section{Dominio fisico}

$\mathrm{Al}$ realizar el análisis considerando a todos los participantes de la muestra total, encontramos que son significativas al modelo las variables edad y nivel de ingresos, las cuales son capaces de explicar un $7.1 \%$ de la varianza de la variable $\mathrm{CV}$ física. Al estratificar el análisis por país, en la población colombiana sólo se mantiene como variable predictora el nivel de ingresos, manteniendo la varianza

Tabla 18. Coeficientes significativos de la recta de regresión.

\begin{tabular}{|c|c|c|c|c|c|c|}
\hline \multirow[t]{2}{*}{ CV Social } & & \multicolumn{2}{|c|}{$\begin{array}{c}\text { Coeficientes } \\
\text { no estandarizados }\end{array}$} & \multirow{2}{*}{$\begin{array}{c}\text { Coeficientes } \\
\text { estandarizados } \\
\text { Beta }\end{array}$} & \multirow[t]{2}{*}{$\mathrm{t}$} & \multirow[t]{2}{*}{ Sig. } \\
\hline & & $\mathrm{B}$ & Error típ. & & & \\
\hline \multirow[t]{5}{*}{ Población total } & (Constante) & 15.723 & 1.030 & & 15.261 & .000 \\
\hline & Edad & -.040 & .016 & -.119 & -2.558 & .011 \\
\hline & Nivel de ingresos & .584 & .245 & .159 & 2.381 & .018 \\
\hline & ¿Tiene ud. pareja? & -.1 .221 & .473 & -.169 & -2.581 & .011 \\
\hline & ¿Usted vive con? & .323 & .130 & .116 & 2.482 & .013 \\
\hline \multirow[t]{3}{*}{ Población colombiana } & (Constante) & 16.195 & 1.629 & & 9.939 & .000 \\
\hline & Nivel de ingresos & .584 & .245 & .159 & 2.381 & .018 \\
\hline & ¿Tiene ud. pareja? & -1.221 & .473 & -.169 & -2.581 & .011 \\
\hline \multirow[t]{4}{*}{ Población peruana } & (Constante) & 14.457 & 1.293 & & 11.181 & .000 \\
\hline & Nivel de ingresos & .580 & .210 & 186 & 2.760 & .006 \\
\hline & ¿Tiene ud. pareja? & -1.968 & .394 & -.349 & -4.995 & .000 \\
\hline & ¿Usted vive con? & .330 & .159 & .144 & 2.073 & .040 \\
\hline
\end{tabular}

Tabla 19. Coeficientes significativos de la recta de regresión por país, CV ambiental.

\begin{tabular}{|c|c|c|c|c|c|c|}
\hline \multirow[t]{2}{*}{ CV Ambiental } & & \multicolumn{2}{|c|}{$\begin{array}{c}\text { Coeficientes } \\
\text { no estandarizados }\end{array}$} & \multirow{2}{*}{$\begin{array}{c}\text { Coeficientes } \\
\text { estandarizados } \\
\text { Beta }\end{array}$} & \multirow[t]{2}{*}{$\mathrm{t}$} & \multirow[t]{2}{*}{ Sig. } \\
\hline & & B & Error típ. & & & \\
\hline \multirow[t]{5}{*}{ Población total } & (Constante) & 11.194 & .705 & & 15.664 & .000 \\
\hline & Edad & -.027 & .011 & -.117 & -2.436 & .015 \\
\hline & Nivel de ingresos & .530 & .114 & .224 & 4.634 & .000 \\
\hline & ¿Tiene ud. pareja? & -.460 & .216 & -.103 & -2.130 & .034 \\
\hline & ¿Usted vive con? & .189 & .090 & .101 & 2.103 & .036 \\
\hline \multirow[t]{2}{*}{ Población colombiana } & (Constante) & 11.201 & 1.170 & & 9.571 & .000 \\
\hline & Nivel de ingresos & .590 & .177 & .225 & 3.327 & .001 \\
\hline \multirow[t]{3}{*}{ Población peruana } & (Constante) & 11.165 & .890 & & 12.545 & .000 \\
\hline & Edad & -.029 & .014 & -.153 & -2.126 & .035 \\
\hline & Nivel de ingresos & .480 & .143 & .237 & 3.347 & .001 \\
\hline
\end{tabular}


explicada a un 7,1\%. En la población peruana se mantiene sólo como variable predictora el nivel de ingresos totales mensuales, aumentando la varianza explicada a un $8.2 \%$ (tabla 16).

\section{Dominio psicológico}

Al realizar el análisis considerando a todos los participantes de la muestra total, encontramos que son significativas al modelo las variable edad, nivel de ingresos, tiene pareja y vive con, las cuales son capaces de explicar un $9.8 \%$ de la varianza de la variable $\mathrm{CV}$ psicológica. Al estratificar el análisis por país, en la población colombiana se mantienen como variables predictoras la edad, nivel de ingresos, tiene pareja o no y con quién vive, disminuyendo la varianza explicada a un $8.9 \%$. En la población peruana se mantienen como variables predictoras la edad y el nivel de ingresos totales mensuales, disminuyendo la varianza explicada en un $8.2 \%$ (tabla 17).

\section{Dominio social}

Al realizar el análisis considerando a todos los participantes de la muestra total, encontramos que son significativas al modelo las variable edad, nivel de ingresos, tiene pareja o no y con quién vive, las cuales son capaces de explicar un $11.9 \%$ de la varianza de la variable CV social. Al estratificar el análisis por país, en la población colombiana sólo se mantienen como variables predictoras el nivel de ingresos $\mathrm{y}$ tiene pareja o no, disminuyendo la varianza explicada a un $8.3 \%$. En la población peruana se mantienen como variables predictoras el nivel de ingresos totales mensuales, tiene pareja o no y con quién vive, aumentando la varianza explicada a un $15.1 \%$ (tabla 18 ).

\section{Dominio ambiental}

Al realizar el análisis considerando a todos los participantes de la muestra total, encontramos que son significativas al modelo las variable edad, nivel de ingresos, tiene pareja o no y con quién vive, las cuales son capaces de explicar un $7.6 \%$ de la varianza de la variable $\mathrm{CV}$ ambiental. $\mathrm{Al}$ estratificar el análisis por país, en la población colombiana sólo se mantiene como variable predictora el nivel de ingresos, conservando la varianza explicada en un $6.4 \%$. En la población peruana se mantienen como variables predictoras la edad y el nivel de ingresos totales mensuales,aumentando la varianza explicada a un $7.3 \%$ (tabla 19 ).

\section{Discusión}

El dominio mejor evaluado por los inmigrantes fue el físico, posiblemente porque la gran mayoría de los participantes son adultos jóvenes, sin grandes dificultades o enfermedades que afecten su salud como en poblaciones más adultas (Urzúa, Bravo, Ogalde y Vargas, 2011), o bien a que los inmigrantes tienen otras preocupaciones más relevantes, donde no considerarían su estado físico como un obstáculo que afecte su percepción de calidad de vida (Basabe, Páez, Aierbi y Jiménez-Aristizábal, 2009; OMS, 2008). No obstante, se debe considerar que las dificultades de acceso a la atención en salud influirían en la dimensión ambiental de la CV, el cual fue el dominio peor evaluado en ambas poblaciones.

En este contexto, se ha reportado que quienes llegan a la ciudad principalmente son inmigrantes que provienen de población urbanizada (Villa y Martínez, 2000) y que sus expectativas materiales son mejorar las condiciones originales desde donde llegan (Torres e Hidalgo, 2009). Las características socioeconómicas de los participantes sugiere que sus ingresos no sobrepasan el mínimo necesario para sustentar una vida totalmente satisfecha en sus necesidades básicas, siendo la base de problemáticas vinculadas con el ambiente en el que se desenvuelven los inmigrantes (Christenson, Zabriskie, Eggett y Freeman, 2006; Stack e Iwasaki, 2009). Resultados similares se han reportado en población chilena (Urzúa, Caqueo-Urízar, 2013), lo que podría evidenciar la fuerza contextual que tiene el entorno en la CV de los inmigrantes más que el hecho mismo de ser migrante.

La nacionalidad se constituyó en una variable importante demostrando que en la población colombiana hay mejores índices de CV en los dominios físico, psicológico y social que en la población peruana participante. Estudios realizados en Chile revelan una percepción negativa hacia la población peruana, sobre la cual pende una serie de prejuicios y que son objeto de discriminación (Cárdenas, 2010), lo cual podría incidir en cómo se relacionan con el contexto y la sociedad chilena, dificultando en cierta medida el proceso de integración, mientras que los colombianos son el grupo que mejores niveles de bienestar reporta, toda vez que establece estrategias de integración o separación. Es decir, mantienen sus valores y estilos de vida, aunque en ocasiones sea a costa de un radical alejamiento del grupo mayoritario (Yáñez y Cárdenas, 2010).

A diferencia de otras investigaciones (Basabe, Zlobina y Páez, 2004), no se encontraron diferencias dadas por el 
nivel de estudios, posiblemente debido a la diferencia entre los estudios cursados por inmigrantes en sus países de origen y la actividad laboral que practican en el de acogida.

El fenotipo fue una característica que afectó en la CV de los inmigrantes que se autodefinían como indígenas más que en los que tenían otras características físicas (blancos, mestizos, mulatos y negros). Actualmente, en la región de Antofagasta se visibilizan actitudes sociales de expresión negativa ante las etnias de origen indígena, que se han dado a lo largo de la historia, debido al contexto sociopolítico que vive la zona, lo cual repercutiría negativamente en quienes pertenecen a esta estructura física. Existen estudios en donde se asocian determinadas características étnicas o raciales a la discriminación, las cuales podrían causar consecuencias graves para el bienestar y la salud de los miembros del grupo devaluado, en términos de síntomas depresivos (Finch, Kolody y Vega, 2000).

La actividad económica fue una de las variables socioeconómicas que más afecta la $\mathrm{CV}$ de los inmigrantes encuestados. Es esperable que quienes se mantienen activos laboralmente o tienen proyectos para comenzar actividades laborales remuneradas como los estudiantes, tengan una mejor percepción de apoyo social tanto del contacto con las personas que se encuentran en estos contextos como de compañeros o colegas, autoridades o agentes de servicios como directores de escuela, jefes, gerentes, AFPs, servicios de salud y otros beneficios que mejorarían la percepción tanto de protección social, apoyo y compañía. No así en quienes no realizan una actividad constante o segura y están en riesgo de dificultades económicas por falta de ingresos, salir de Chile por no tener un trabajo con contrato, o no cumplir con las expectativas de ganancia que se tenían al comenzar el viaje hacia otro país.

El nivel de ingresos mensuales afecta todas las variables. Según Espínola (2007), se mantiene la evidencia de que el nivel de ingresos con que se cuenta para satisfacer necesidades básicas, es el elemento determinante del trato, favorable o desfavorable en una sociedad de mercado. En este estudio, la mayoría de los participantes no percibe ingresos suficientes para satisfacer sus necesidades básicas y además enviar remesas a sus familias, generando muchas veces un quiebre entre las expectativas e ilusiones comprendidas antes de emprender el viaje y con la realidad a la que finalmente llegan, encontrándose con una dificultad para obtener empleo, los que además se caracterizan por tener una baja remuneración, poca cualificación, alta inestabilidad, son repetitivos y conllevan pocas o nulas posibilidades de ascenso (Gertrudis, 2007). En muchas ocasiones, los migrantes optan por trabajos con salarios mínimos y que no permiten cubrir las necesidades básicas, lo que se ha relacionado con altos índices de estrés, sumado al rechazo y hostilidad por parte de la población de acogida, así como por la ausencia de apoyo social (Chung, 2002; Finch y Vega, 2003; Sandin y Valiente, 1999).

Se acepta la hipótesis donde se plantea que aquellas personas con permiso de residencia tendrían mejor $\mathrm{CV}$ ambiental. Suponemos que esto sucede debido a que al estar regularizados, los inmigrantes pueden tener mejor calidad de acceso a la salud, asistencia social y oportunidades laborales, proporcionándoles mayor estabilidad. En el estudio de Hernández, Pozo y Alonso (2004) hecho con marroquíes en España se plantea que el tener problemas en vivienda, documentación o percepción de prejuicio étnico afectaría negativamente en el bienestar subjetivo de la población inmigrante; el recibir estos beneficios es clave para acceder a la satisfacción de necesidades básicas en la población inmigrante y los niveles de calidad de vida. Es importante conocer estos resultados para la población que no se encuentra regularizada ya que las condiciones cotidianas que viven distan de las de sus compatriotas regularizados, lo cual sería una variable interesante de aclarar en futuras investigaciones. Asimismo, si se estima que el proceso migratorio es difícil y precario para aquellos inmigrantes que cumplen con la entrada regular al país, puede suponerse que el proceso para aquellos que tienen un ingreso de forma ilegal es aún más precario y complejo, dificultándose el acceso y cabida a servicios como al sistema de salud pública o el optar a trabajos con contratos legales. $\mathrm{Y}$ es así como los eventos mencionados anteriormente implican esfuerzo y lucha constante para enfrentar las adversidades que se presentan en la realidad que viven, lo cual afectaría de una u otra manera el bienestar ya sea físico, social, ambiental o psicológico. A partir de los resultados se concluye que el hecho de obtener un empleo que entrega un salario mínimo o elevado, encontrarse con los permisos regulares o irregulares, y el tiempo que llevan viviendo en la ciudad, entre otras dificultades del proceso de adaptación durante la migración, repercutirán de manera positiva o negativa en la calidad de vida de los inmigrantes así como en su salud mental.

Por otro lado, el grado de contacto que tienen los inmigrantes con personas de Chile se relaciona con los dominios de calidad de vida, de manera que quienes tienen relaciones más cercanas con personas de Chile reportan mejores niveles de calidad de vida que quienes no habitúan el contacto con personas chilenas. El apoyo social percibido y el sentirse pertenecientes a una sociedad se relaciona con mejores estrategias de adaptación, menores niveles de estrés, y por 
ende una mejor inserción en el nuevo contexto social al que se integran los inmigrantes.

El tener pareja y vivir con alguien más muestra que en la calidad de vida de los inmigrantes influirían de forma positiva, ya que estas personas tenderían a mostrar mejores niveles de calidad de vida, específicamente en sus dominios psicológico y social. Se reconoce que a medida que el contacto social aumenta debería existir un cambio en la salud mental y en el bienestar subjetivo de los inmigrantes, la disponibilidad de vínculos estrechos con quienes poder compartir problemas y vivencias personales (Hernández et al, 2004), el sentirse pertenecientes a un grupo que ofrece contención emocional, intimidad en la pareja, facilitaría el proceso de adaptación integrándose quienes son nuevos en un país a la comunidad de una forma positiva.

Dentro de las principales limitantes del estudio, encontramos en primer lugar un déficit de investigaciones sobre el tema en Chile y en otros países latinoamericanos donde se desarrollan dinámicas migratorias similares a las de nuestro país, obstaculizando el contraste de resultados o la búsqueda teórica de lo que sucede con los inmigrantes en contextos similares.

Por otro lado, acceder a la población inmigrante con situación legal irregular es una tarea difícil que requiere trabajo de campo exhaustivo, para que quienes tienen esta característica tengan la confianza de revelar a alguien su condición, la cual mantienen resguardada incluso para sus propios compatriotas, lo que dentro del marco de esta investigación no se llevó a cabalidad debido a los plazos que se tenían que cumplir durante el muestreo. Esto hace que la cantidad de personas que tienen una situación administrativa irregular y fueron participantes de este estudio no sea representativa de quienes viven esta situación y se mantienen dentro del anonimato, y se desconozca su situación y condiciones de vida, así como los factores que afectarían la calidad de vida de la población inmigrante de estas características.

Creemos que la información presentada aporta a la comprensión de la manera en que viven, se integran y desenvuelven los inmigrantes en el país residente y los factores asociados a las condiciones de vida, vislumbrándose la necesidad de realizar nuevos estudios que permitan explorar la percepción de los chilenos frente a los inmigrantes, en la mira de mejorar las condiciones y bienestar de los inmigrantes.

\section{Referencias}

Achotegui, J. (2004). Emigrar en situación extrema: el Síndrome del inmigrante con estrés crónico y múltiple (Síndrome de Ulises). Norte de salud mental, 21, 39-52.

Basabe, N., Zlobina, A., y Páez, D. (2004). Integración sociocultural $y$ adaptación psicológica de los inmigrantes extranjeros en el País Vasco. Recuperado desde http://gvas.euskadi.net/pub/gv/estudios sociológicos/ csv15.pdf

Basabe, N., Páez, D., Aierdi, X. y Jiménez-Aristizábal, A. (2009). Salud e Inmigración. Aculturación, bienestar subjetivo y calidad de vida. Ikuspegi. Observatorio Vasco de Inmigración.

Benítez, S., Guardia, J. y Urzúa, A. (2014). Factorial structural analysis of the Spanish version of WHOQOLBREF: an exploratory structural equation model study. Quality of Life Research, 23, 2205-2212.

Bernacki, P. y Waldorf, D. (1981). Snowball Sampling. Sociological Methods and Research, 10, 141-163.

Bourguignon, D., Seron, E., Yzerbyt, V. y Herman, G. (2006). Perceived group and personal discrimination: differential effects on personal self-esteem. European Journal of Social Psychology, 36, 773-789.

Branscombe, N., Schmitt, M. y Harvey, R. D. (1999). Perceiving pervasive discrimination among African-Americans: Implications for group identification and well-being. Journal of Personality and Social Psychology, 77, 135-149.

Cárdenas, M. (2010). Forms of ethnic prejudice: Assessing the dimensionality of a Spanish language version of the Blatant and Subtle Prejudice Scale. Psicothema, 22, 118-124.

Cano, V. y Soffia, M. (2009). Los estudios sobre migración internacional en Chile: apuntes y comentarios para una agenda de investigación actualizada. Papeles de población, 15, 129-167.

CEPAL/CELADE (2006). Migración Internacional. Observatorio Demográfico. América Latina y el Caribe. $\mathrm{N}^{\circ} 1$, abril, 2006. Santiago, Chile.

CEPAL (2000). La migración internacional y el desarrollo en las Américas. Simposio sobre migración internacional en las Américas. San José, Costa Rica, septiembre de 2000.

Cerrutti, M. (2005). La migración peruana a la ciudad de Buenos Aires: Su evolución y características. Población de Buenos Aires, 7-28.

Contreras, H. (1984). ICV=1-3.125 (15 y 55). Un modelo cuantitativo de calidad de vida. Nueva Sociedad, 75, 33-41.

Chung, H. (2002). The challenges of providing behavioral treatment to Asian Americans. Western Journal of Medicine, 176, 222-224.

Clínica Psiquiátrica de la Universidad de Chile (2008). Diagnóstico y factibilidad global para la implementación de politicas globales de salud mental para inmigrantes de la zona norte de la Región Metropolitana. Santiago: Clínica Psiquiátrica de la Universidad de Chile, Ministerio de Salud, Organización Internacional para las Migraciones (OIM).

Christenson, O., Zabriskie, R., Eggett, D. y Freeman, P. (2006). Family acculturation, family leisure involvement, and family functioning among Mexican-Americans. Journal of Leisure Research, 38(4), 475 - 495.

Espínola, G. (2007). Buscando arraigo. Inmigrantes y vivienda: otra forma de exclusión. Universitas. Revista de Filosofia, Derecho y Politica, 6, 91-106.

Espinoza, I., Osorio, P., Torrejón, M., Lucas-Carrasco, R. y Bunout, D. (2011). Validación del cuestionario de calidad de vida (WHOQOLBREF) en adultos mayores chilenos. Revista Médica de Chile, 139, 579-586.

Fajardo, M., Patiño, M. y Patiño, C. (2008). Estudios actuales sobre aculturación y salud mental en inmigrantes: Revisión y perspectivas. Revista Iberoamericana de Psicología: Ciencia y Tecnología, 1, 39-50.

Finch, B. K. y Vega W. A. (2003). Acculturation stress, social support, and self- rated health among Latinos in California. Journal of Immigrant Health, 5, 109-17. 
Finch, B. K., Kolody, B. y Vega, W. A. (2000). Perceived discrimination and depression among Mexican-Origin adults in California. Journal of Health and Social Behavior, 41, 295-313.

Gertrudis, M. (2007). Condiciones laborales y precariedad de los inmigrantes. El caso de los colombianos en tres comarcas de la provincial de Barcelona. Fundación CIDOB.

Hernández-Plaza, S., García-Ramírez, M., Camacho, C. y Paloma, V. (2010). New settlement and wellbeing in oppressive contexts: A liberation psychology approach. In C. Stuart (Ed.), The psychology of global mobility. International and Cultural Psychology Series (pp. 235-256). New York: Springer.

Hernández, S., Pozo, C. y Alonso, E. (2004). Apoyo social y bienestar subjetivo en un colectivo de inmigrantes ¿Efectos directos o amortiguadores? Boletín de Psicología, 80, 79-96.

Lucas-Carrasco, R. (2012). The WHO quality of life (WHOQoL) questionnaire: Spanish development and validation studies. Quality of Life Research, 21, 161-165.

Mesch, G., Turjeman, H. y Fishman, G. (2008). Perceived discrimination and the well-being of immigrant adolescents. Journal of Youth and Adolescence, 37, 592-604.

Murillo, J. y Molero, F. (2012). Factores Psicosociales Asociados al Bienestar de Inmigrantes de Origen Colombiano en España. Psychosocial Intervention. 21, 319-329.

OMS (2006). Derecho internacional sobre migración. Glosario sobre migración, $N^{\circ} 7$, Suiza.

OMS (2008). Salud de los migrantes. $61^{a}$ Asamblea Mundial de la Salud. Punto 11.9 del orden del día provisional.

Sánchez, G. y López, M. (2008). Ansiedad y modos de aculturación en la población inmigrante. Apuntes de psicología, Universidad de Sevilla, 26, 399-410.

Stefoni, C. (2011). Perfil migratorio de Chile. Buenos Aires, Argentina. Organización internacional para las migraciones.

Sandin, B. y Valiente, R. (1999). El estrés crónico (III): estrés crónico asociado a factores socioculturales. En B. Sandin (dir.), El estres psicosocial: conceptos y consecuencias clínicas (pp. 245-316). Madrid: Klinik.

Stack, J. A. C. e Iwasaki, Y. (2009). The role of leisure pursuits in adaptation processes among Afghan refugees who have immigrated to Canada. Leisure Studies, 28(3), 239-259.

Torres, A. e Hidalgo, R. (2009). Los peruanos en Santiago de Chile: transformaciones urbanas y percepción de los inmigrantes. Polis, Revista de la Universidad Bolivariana, 8, 307-326.

The WHOQOL Group (1995). The World Health Organization Quality of life assessment (WHOQOL): Position paper from the world health organization. Social Science and Medicine, 41, 1403 - 1409.

The WHOQOL Group (1998). Development of the World Health Organization WHOQOL-BREF quality of life assessment. Psychological Medicine, 18, 551-558.

Urzúa, A., Bravo, M., Ogalde, M. Vargas, C. (2011). Factores vinculados a la calidad de vida en la adultez mayor. Revista Médica de Chile, 139, $1006-1014$

Urzúa, A. y Caqueo-Urízar, A. (2012). Calidad de vida: Una revisión teórica del concepto. Terapia Psicológica, 30, 61-71.

Urzúa, A. y Caqueo-Urízar, A. (2013). Estructura Factorial y valores de referencia del WHOQoL-Bref en población adulta chilena. Revista Médica de Chile, 141, 1547-1554.

Valiente, R., Sandín, B., Chorot, P., Santed, M. y González de Rivera, J. (1996). Sucesos vitales mayores y estrés: Efectos psicopatológicos asociados al cambio por migración. Psiquis, 17, 211-230.

Vilar, E. y Eibenschutz, C. (2007). Migración y salud mental: un problema emergente de salud pública. Revista Gerencia y Salud, 6, 11-32.

Villa, M. y Martínez J. (2000). Tendencias y patrones de la migración internacional en América Latina y el Caribe. CEPAL-Celade.

Yáñez, S. y Cárdenas, M. (2010). Estrategias de aculturación, indicadores de salud mental y bienestar psicológico en un grupo de inmigrantes sudamericanos en Chile. Salud y Sociedad, 1, 51-70.

Zarza, M. y Sobrino, M. (2007). Estrés de adaptación sociocultural en inmigrantes latinoamericanos en Estados Unidos vs. España: Una revisión bibliográfica. Anales de psicología, 23, 72-84. 